\title{
Life Markers in Biographical Narratives of People from Three Cohorts: A Life Span Perspective in Its Historical Context
}

\author{
Alexander Grob $^{a}$ Franciska Krings $^{b}$ Adrian Bangerter ${ }^{b}$ \\ a University of Bern, b University of Basel, Switzerland
}

\begin{abstract}
Key Words
(Auto-)biography · Life markers · Perceived control - Life span development · Historical context $\cdot$ Narrative $\cdot$ Socio-historical change
\end{abstract}

\begin{abstract}
Human development is often understood as an interplay between biological, sociohistorical, and social factors, as well as individual developmental actions. However, historical influences on development have rarely been investigated. The present study discusses societal change in the course of this century and investigates its impact on the life course by analyzing biographical narratives. This impact is illustrated by results from a study where participants from three birth cohorts (1920-25; 1945-50; 1970-75) were interviewed about important markers in their experienced and expected biographies. Although distribution of life markers over the life span was analogous across cohorts, participants from the younger cohorts perceived themselves as having more control on setting important life markers across their biographies. Their narratives referred more often to personal and less often to contextual and sociohistorical themes.
\end{abstract}

The research was supported by the Swiss National Science Foundation within the Swiss Priority Programme 'Switzerland: Towards the Future' (5004-47766). Parts of the manuscript were written while the first author spent a visiting year at the University of Illinois at Urbana-Champaign granted by the SNSF (1145780.95) and while at the University of Bonn. We would like to thank Barbara Rogoff, Klaus Opwis, Markus Stöcklin, and four anonymous reviewers for most helpful comments on an earlier version of the manuscript.

\section{KARGER (c) 2001 S. Karger AG, Basel \\ Fax +4161306 1234 \\ E-Mail karger@karger.ch \\ www. karger.com}

Alexander Grob

Institute of Psychology, University of Bern

Muesmattstrasse 45, CH-3000 Bern (Switzerland)

Tel. +41 316314037 , Fax +41316318212

E-Mail Alexander.Grob@psy.unibe.ch 
Recent theories of life-span development agree that human development is best described by an interplay between biology, culture, and individual action [see for example, Baltes, 1997; Brandtstädter, 1997; Bronfenbrenner, 1979; Lerner, 1996]. This notion has been taken for granted since Havighurst's formulation of developmental tasks [1948] and Erikson's description of the life cycle [1959]. However, even though cultural relativity was acknowledged in both formulations, a stable impact of biology and culture on development was assumed. This assumption is questionable. The course of the twentieth century has been marked by a number of monumental and far-reaching societal changes. The relevance of these changing societal and social settings for individual development was impressively brought to scientific awareness by Glenn Elder's [1974, 1998] work about the lives of children of the Great Depression.

On a broad level, the notion that the individual is responsible for determining his or her own life course seems to be taken for granted in industrialized Western societies. It seems that these societies no longer uniformly define the organization of the life course. Developmental tasks seem to be increasingly less given by society and, furthermore, less bound to specific ages. Instead, the individual has to construct his or her own biography by formulating personal projects and goals [Baumeister, 1991]. This developmental understanding makes human beings more than ever architects of their own fortune and confronts them with a new emerging pressure, characterized by the necessity of permanently realizing oneself in a new and original manner. To meet this pressure, individuals are expected to choose a few distinct goals and projects from a large number of possibilities along their life course, and to decide themselves on appropriate ways to successfully realize them. Such an understanding of development requires a high degree of self-responsibility and a strong belief in available psychosocial resources.

We acknowledge that this account of a movement towards increasing individual choice may not be relevant for all Western societies or even for all social classes or subcultures of a given society (e.g., for people living in poverty, the idea of individual choice may be far from relevant). Therefore, although the account presented above is somewhat stylized [for discussion see Held, 1986; Mayer, 1986], we will show how these assumptions can be supported by examining biographical narratives. We investigated the relation between the historical context and the conceptualization of life of people from three different cohorts spanning most of the twentieth century in Switzerland. Although each participant's life is unique, we assume cohort-specific commonalities in biographies. The commonality consists in how people reconstruct their biographies and how they construct their future life course. We assume a major shift in this process which goes from a more system-centered and deterministic conceptualization of life for people from older cohorts towards a more self-centered and agentic conceptualization of life for people from younger cohorts. This thesis will be illustrated by referring to biographical narratives as situated, subjective reconstructions of the life course.

\section{Individualization and the Institutionalization of the Life Course}

Contemporary theories of modernity see this change as part of a process affecting Western societies over the last three to four centuries called individualization, which can be described as a societal movement of increasing choice and possibilities for the individual [Beck, 1986; Zapf, 1995] or of an increasing 'release of the individual from (status and local) bonds' [Kohli, 1985, p. 3; translated by the authors]. One aspect of this

$\begin{array}{ll}\begin{array}{l}\text { Human Development } \\ 2001 ; 44: 171-190\end{array} & \text { Grob/Krings/Bangerter } \\ \end{array}$


process is what Kohli [1985; 1986] calls the institutionalization of the life course. The argument is that the life course has become increasingly organized along a chronological dimension, i.e. it has become structured by age, along the lines of institutions such as schooling and retirement [Kohli \& Meyer, 1986].

The origins of the institutionalization of the life course can be traced in part to the decline of human mortality in the 19th century [Imhof, 1986]. For example, until the middle of the 19th century, death was highly probable in all phases of life. War, poverty, and famine were omnipresent and took a heavy toll on the population. Fifty percent of children did not experience adult life. Hareven [1995], for example, mentioned that the culturally expected life course for women in the late 19th century (marriage, motherhood, parenting together with a husband, widowhood) was experienced by only those 44 percent of women who survived beyond age 15 .

Today, for the vast majority of the population in the Western world, death occurs late in life after a long phase characterized by a high degree of security. In other words, life has become chronologically predictable and subject to planning. Kohli [1986] proposes that life can be segmented into three major periods, namely preparation for an occupation, working life, and retirement. This standardization of the life course could be observed in different life domains until the early seventies. Since then, a number of changes have occurred in the family and work domains, pushed by the civil unrest and economic crises of the time. Several labels exist in the literature for this trend, including notions of postmodernity, postindustrial society, de-institutionalization of the life course [Held, 1986], or the idea of an age-irrelevant society [Neugarten \& Hagestad, 1976]. Debate focuses on whether the life course remains standardized or whether this standardization has been eroded in favor of a pluralization of life-styles and subcultures [Held, 1986; Zapf, 1995].

It is neither our primary goal nor the place to draw a comprehensive picture of the historical changes which affected human lives since the beginning of the 20th century, and we will not discuss the institutions which emerged along with these changes [see for example Mayer, 1986; Sørensen, 1986]. Nevertheless, a few historical changes are noteworthy because they impressively exemplify how proximal developmental settings have changed within the last decades.

\section{Three Patterns of Sociohistorical Change}

As examples, we refer to three patterns of sociohistorical change: The employment sectors, family types, and female participating in the labor force.

Employment Sectors. In modern societies, profession is a crucial marker for life. The employment sectors have varied substantially during the last centuries. Modern societies show a uniform sequence of development in employment sectors: The agrarian sector was the most prevalent over centuries, followed by the industrial sector and finally by the service sector at the end of the 20th century. The speed of change in these sectors, and hence the extensive reorganization of societies, is tremendous. For example, within 40 years, the agrarian sector changed from being the most prevalent employment sector in 1950 to the least prevalent employment sector in 1990 in France, Italy, Spain, Poland, Russia, former Czechoslovakia, and Japan [recalculated statistics, originally presented by Kaelble, 1997]. In these countries, the agrarian sector lost normativity within one and a half generations. In other countries, the restructuring of the employ- 
ment sector occurred with a comparable rapidity, but at different times. As a consequence, most families were forced to migrate, in general from rural to urban or suburban settings. There they encountered new labor market structures, new housing environments, new structures of neighborhood relations, and new urban leisure facilities.

Family Types. Changes in the employment sectors went along with new family constellations. For example, for the USA, Hernandez [1993] reported changes of the prevalence of different family types between 1790 and 1990. Two-parent farm families were by far the most prevalent family type over decades. A steady decrease of this family type started in 1830 . In 1990 , less than 5 percent of children below age 17 lived in two-parent farm families. These changes also reflect the diminishing importance of the agrarian employment sector. In parallel, two-parent non-farm families with a full-time working father and a full-time homemaker mother rapidly increased, resulting in the most prevalent family type between 1910 and 1970. This family type almost disappeared in the 1990s, replaced by dual-earner families. After World War II, only 20 percent of children and adolescents lived in dual-earner families, compared with 70 percent in 1990. The increase of dual-earner families was likely due to the economic growth after World War II, the need for employees in a service-oriented economy, the women's liberation movement and the greater sensitivity towards gender equality in private and public domains. Since the seventies, one-parent families started to become more prevalent. Towards the end of the 20th century, this family type became as frequent as traditional two-parent families. These numbers reflect the changes in the USA. However, for the Western world as a whole, the pattern of family structures also changed, but within different time frames [Kohli, 1985].

Female Labor Force Participation. An increase of female labor force participation is evident since the 1950s. According to the U.S. Bureau of the Census [1997, especially Tables 631 and 632] the increase varies according to marital status and the presence of children in the household. The most dramatic increase occurred for women with children aged 6 and younger. One fifth of these women participated in the labor force in 1960. At that time, these were predominantly non-Causasian women. This ratio increased to almost two thirds in 1996 with also no differences with respect to ethnicity. Since 1960, more women who were widowed, divorced, or who lived separated from a spouse and had one child aged 6 or younger participated in the labor force than women with a partner. Children's age barely influences their mothers' participation in the labor force: In 1996, about 60 percent of women with a child younger than one year worked outside the household.

\section{Psychological Impact of Societal Change}

The question arises of what effects these changes have on human development. In order to answer this question, we first assume a loose coupling between three levels of social reality: societal changes, proximal developmental settings, and individual development. What effects do societal changes have on proximal developmental settings? The following examples illustrate changes in developmental settings as a consequence of changes in macrosocial conditions. First, at the end of the 20th century, it seems to be accepted that other persons than parents are involved in raising children. Furthermore, parents do not have a single life context, but participate in multiple and often unrelated contexts at work, at home, with friends, in many leisure activities and so on. Grandpar-

$\begin{array}{ll}\begin{array}{l}\text { Human Development } \\ 2001 ; 44: 171-190\end{array} & \text { Grob/Krings/Bangerter }\end{array}$


ents are not expected to step in for parenting; they strive for their own goals after retirement. In general, children have other professions than their parents had. Mothers are often the first in a family's history who work outside of the home and pursue a career. Leaving one's hometown with the purpose of finding better job opportunities has become the rule. We do not insist on the generality of such examples; however it seems clear that they are representative of a number of recent trends [Beck, 1986] that have highly significant consequences for individual development.

One such consequence may be the fact that, at the beginning of the 21 st century in the Western world, only marginal practical knowledge can be successfully transferred from one generation to the next [Grob, 1998]. In other words, the practical knowledge people accumulated in one generation (and which constitute the 'wisdom' of that generation) does not guarantee success anymore for the subsequent generation. We assume that these processes enhance the pressure on individuals to determine and accept responsibility for their own lives [Baumeister, 1991]. This in turn might contribute to an increased focus on one's own individuality.

Connections between societal change and individual life courses are often studied in social science with data about perceptions of normative transitions, e.g., changes in mean age and variance of first marriage, birth of first child, retirement, etc. [Neugarten, 1979; Zepelin, Sills \& Heath, 1986-87]. In general an increase of variance across time is interpreted as an indicator of de-standardization [Settersten \& Hagestad, 1996a, b]. Our approach investigates the same question but from an 'inner' perspective. We assume an effect of sociohistorical change on biographies, especially what people experience as important life markers and how people talk about their biographies, i.e., how they conceptualize their lives.

\section{Life Markers and Perceived Control}

Fend [2000] argued that the process of increasing individualization made people the central agent in shaping their lives. Furthermore, if it is true that individuals today are expected to create a unique life course, then the degree to which people experience a sense of control over their lives becomes a crucial factor in coping with this demand. Reviews of cross-sectional and longitudinal research on developmental changes in control perceptions have reported contradictory findings ranging from increases in personal control to no variations to decreases across the life span [Kogan, 1990; Lachman, 1986; Welch \& West, 1995]. In general, people strive for control in domains that are personally relevant [Berry \& West, 1993]. The more relevant a life domain, the more important it is to have a sense of psychological control over it. However, no study exists to our knowledge which would provide an answer to the question of possible sociohistorical influences on individual control perceptions.

Skinner [1996] has outlined that many control constructs exist in the literature. We will focus on control expectancy which reflects the extent to which a person feels personally empowered over a specific outcome [Grob, 2000]. Grob, Little and Wanner's [1999] study over an age range between 14 and 85 years indicates that participants at all ages reported quite low amounts of control expectancy for societal concerns (i.e., local political decisions, natural environmental problems) and, furthermore, that this low level of perceived control decreased steadily with age. However, the expectation of attaining one's goals in social domains (i.e., maintaining harmony within a close rela- 
tionship) and personal domains (i.e., physical appearance) was quite high. The age trends indicated that such expectations peak between the ages of 30 and 40 and decrease thereafter, but remain positive even in old age. Although the data were very consistent and shed light on domain-specific trajectories of different control aspects across the life span, the design did not allow conclusions about possible sociohistorical influences on control expectancies. Hence, this question has to be studied with a different approach.

\section{Biographies of People}

Social scientists repeatedly have claimed that societal changes substantially affect people's lives. In psychology, this claim is also largely shared, but has been rarely tested. Nevertheless, there are approaches in psychology that investigate the issues of sociohistorical conditions, proximal settings, and individual development, either in longitudinal research [for example, Elder, 1998; Magnusson, 1993], or research on societal expectations [for example, Heckhausen \& Krüger, 1993; Settersten, 1997], or in cross-cultural research [for example, Church \& Lonner, 1998; Triandis, 1997]. To our knowledge, however, few studies exist which investigate how societal changes affect the life courses of people from different generations [see however Elder, 1998, for an overview; Grundmann, 1996], and consequently how individuals from different generations perceive having control over their lives.

Taking into account Elder's [1998] principle that the life course is shaped by historical factors, we decided to study the biographies of participants from three age cohorts in Switzerland; i.e., people who were born Between The Wars (BTW; born 1920-1925), people who were Early Baby Boomers (EBB; born 1945-1950), and people from the ' $G E$ neration $X$ ' (GEX; born 1970-1975). The BTW subjects experienced infancy and early childhood during a time of economic growth, whereas their late childhood and adolescence was during economic depression and young adulthood during World War II. In contrast, the EBB subjects experienced their infancy, childhood, and adolescence during postwar economic growth, in parallel with new emerging family patterns and a shift in female labor force participation. This cohort was exposed in late adolescence and young adulthood to the women's liberation movement and the civil unrest of the 1960s. The GEX subjects were born in a time of economic consolidation. Many of them experienced material security during childhood, which often resulted in consumerism and materialism in adolescence and young adulthood. However, this cohort was the first that was confronted with ecological problems and, due to the mass media and increasing worldwide communication, the experience of globalization while they were adolescents.

These three cohorts can be considered as generations in Mannheim's [1952] sense. Moreover, the fact that the positioning of each cohort is 25 years apart makes them successive generations (i.e., participants from a given generation are children of members of the preceding generation), and thus ideal points of entry for assessing social and historical change and its effect on the life course. Taken together, the lives of the members of these cohorts span most of twentieth century Swiss history. We expect to find traces of the societal changes discussed above in their biographies. Thus, in the following section, we discuss the use of biographical narratives as a method for analyzing such changes.

$\begin{array}{ll}\begin{array}{l}\text { Human Development } \\ 2001 ; 44: 171-190\end{array} & \text { Grob/Krings/Bangerter } \\ \end{array}$




\section{Narrative Construction of Biographies}

Analysis of narratives is increasingly employed in psychology and related disciplines [see for example Sarbin, 1986; Bamberg, 1997a], including in developmental psychology [Bamberg, 1997b], where biographical narrative is analyzed in its specificity [Jüttemann \& Thomae, 1987, 1998; Straub, 1989]. The biographical narratives in the present corpus incorporated stories, anecdotes, opinions, self-presentations, and many other conversational forms. We are interested in relating biographical narratives to the historical contexts they reflect.

A first question arising in this regard is that of autobiographical memories: In what way can such memories be used to tap generation-specific collective experience? The structure of autobiographical knowledge seems to be strongly influenced by the self: Knowledge structures are constructed according to personal themes as expressed in plans and goals of previous selves [Conway, 1997]. In this sense, autobiographical knowledge can be understood as a personal record of past selves.

A common finding of studies that investigate the distribution of autobiographical memories over the life span is that the largest amount of remembered autobiographical events occur between approximately 10 and 25 years of age [Rubin, Wetzler \& Nebes, 1986; Conway 1997]. This so-called reminiscence peak in autobiographical memory therefore represents a large corpus of experiences that occurred during one of life's major transitions; i.e., the transition from childhood to adulthood. One important aspect of the reminiscence peak may thus be developmental: The period is known as being critical in the formation of a stable self and a unique identity [Erikson, 1959] and solving crucial developmental tasks [Havighurst, 1948]. Thus, the reminiscence peak may contribute significantly to the formation of a personal identity. These conclusions are pushed further by Fitzgerald [1988], who argues that reminiscence is constituted by especially vivid memories which are organized in the form of narratives about the self.

Conway [1997; referring to Mannheim, 1952] proposed that the reminiscence peak may also be critical in supporting the formation of generational identity; i.e., shared cultural experiences, shared conceptual knowledge, or shared experiences of a type of event within a certain generation. Mannheim [1952] pointed out that biological or chronological commonalities are not a sufficient basis for defining generation identity: Individuals from one generation do not only share the same socio-historical context, but also collective plans and goals. Only through this shared knowledge can individuals growing up under the same social-historical conditions become a generation. Thus, the reminiscence peak in autobiographical memory may provide a basis for personal and generational identity.

A second aspect of the relation between biographical narratives and the historical context deals with features of narrative discourse and how they can be used in the present research context [Rosenthal, 1993]. A heuristic for identifying generational specificity in biographies is to focus on structural similarities in narratives of participants of a given generation, which distinguish them from members of other generations [Kleining, 1998]. These similarities range from thematic aspects such as topic management to pragmatic aspects such as perspective, actors, attributions and the like.

Thematic similarities and differences can be identified on a global level by identifying similar categories of life markers. For example, in younger cohorts, educational life markers may be mentioned more frequently, reflecting the preoccupation of these 
persons with education and possibly reflecting the increasing salience of education (especially ongoing education) in society.

On a more detailed level of analysis, one can look at the related themes participants talk about when narrating (for example) educational experiences. Thus, members of the BTW cohort may talk about the societal conditions in which they completed schooling, whereas members of the GEX cohort may talk about more personal aspects, such as interest in particular subjects. In this way, analogous markers (e.g., education) may be associated with very different themes in narratives.

\section{Accounts of Three Cohorts of Swiss Citizens}

Four main questions guided our study. Each question is discussed with respect to age and cohort specificity.

First, how are life markers distributed across the life span? We expect a reminiscence peak for the time around late adolescence in the reconstructed biographies for each cohort.

Second, to which extent do people perceive themselves as agents in their lives? People from the youngest cohort are expected to show a more individualistic and selfrelated concept of the life course than subjects from older cohorts. Hence, we assume that participants from this cohort perceive themselves as having more control over their development than participants from older cohorts. This result is expected to vary over the life span, with an increase of reporting of personal control from childhood through middle adulthood, and afterwards a steady decrease into old age is expected.

Third, what specific events are perceived as important life markers? Assuming that macrosocial conditions with which individuals are faced during childhood, adolescence, and young adulthood crucially affect the life course, we assume that people from younger cohorts are more affected by the individualization processes that take place in modern societies. Thus, people from older cohorts should report more traditional developmental tasks (perceived as life markers across the life span) than people from younger cohorts. Traditional developmental tasks are, for instance, attaining autonomy from parents or decision for an occupation in late adolescence, getting married and having children in early adulthood, managing the household (for women) and pursuing a professional career (for men) during middle adulthood. People from older cohorts should show a developmental concept which is more oriented to the satisfaction of traditional developmental tasks as well as societal and familial demands than the developmental concept of younger cohorts. If this pattern holds, it would indicate that people from younger cohorts are more likely forced to decide about their future life course by choosing important goals and appropriate ways to their successful realization. People from younger cohorts would thus value the realization of developmental tasks only to the extent that they contribute to personal fulfillment and self-actualization.

Fourth, focusing on education as a significant theme: With which developmental contexts is this life marker associated? When the members of the different cohorts report the same normative life markers - getting an education - will they associate it with different developmental contexts? For example, individuals from later cohorts may discuss educational markers with a more individualistic approach in their biographical narratives.

\begin{tabular}{|c|c|}
\hline 178 & $\begin{array}{l}\text { Human Development } \\
2001: 44: 171-190\end{array}$ \\
\hline
\end{tabular}


Seventy-five participants were recruited by mail from a randomly drawn pool obtained through the administrative register of the city of Berne, Switzerland (twentyfive per cohort; BTW, born 1920-25: 14 men, 11 women; EBB, born 1945-50: 11 men, 14 women; GEX, born 1970-75: 12 men, 13 women; overall response rate $=23 \%)^{1}$.

Participants were approximately 25,50 , or 75 years old at the time the study was conducted (winter of 1997-1998). All participants were interviewed according to the following four life periods: childhood to young adulthood (0-25 years of age), young to middle adulthood (25-50 years of age), middle adulthood to old age (50-75 years of age), and old age to very old age (over 75 years of age). Thus, depending on their age, participants responded from different temporal perspectives [see design in figure 1, and also De Vries \& Watt, 1996].

The data were collected in the course of a semi-structured 90-minute interview. The participant briefly described his or her current life situation, and then described life markers that significantly affected his or her life. First, the concept of life markers was explained: 'Now we would like to talk about events that were important for your life. This means events which you think affected your life significantly, or events that had a formative influence on your life, or that turned your life in a particular direction.' Then the participant was questioned according to each life period. For example, the question for the first life period from birth to age 25 was: 'If you think of the time of your early childhood until about age 25: Which events during this time period significantly affected your further life course and personal development?' For prospective assessment as for example for the life period after age 75 the question was reformulated: 'If you now think of the time after age 75: Which events, do you think, will affect your further life course or your further personal development after age 75?'

The interview was additionally supported by using a visual aid, a 'life graph', which consisted of a large two-dimensional grid showing a time line of age in years, numbered from 0 to 100 and the following life domains: society, education/work, leisure/culture, family/friendship, and personal/health, to make the task more manageable. It was emphasized that participants need not mention life markers from all domains, if none occurred. All events mentioned by participants were entered (by marking a few words) on the grid defined by time of onset and life domain. The life period between 0 and 25 was assessed first, followed by the others in chronological order. In addition, control over life markers was assessed: After all life markers of a certain life period had been collected, participants were asked to select those events they perceived as personally controlled as well as those they perceived as not personally controlled at all.

The interview transcripts were coded by two independent coders, and final coding decisions were established through consensus. Text segments corresponding to the nar-

${ }^{1}$ Most members of the $B T W$ cohort were married (56\%), and 20\% were widowed. About one half had finished junior high school (48\%) and 30\% had attended and/or finished high school. Sixty-eight percent of the BTW members had completed vocational training after school. For the $E B B$ cohort, $36 \%$ were married, $28 \%$ divorced, and $24 \%$ of the nonmarried persons lived with a partner. Sixty percent had finished junior high school and $16 \%$ had finished high school. Seventy-two percent of EBB members had completed vocational training after school and $16 \%$ had a university degree. For the $G E X$ cohort, most persons were single (56\%); $32 \%$ reported living with a partner. Fourty-four percent had finished junior high school and another $52 \%$ had finished high school. After school, $44 \%$ had completed vocational training and $48 \%$ had graduated from university or were at university at the time of the study. 


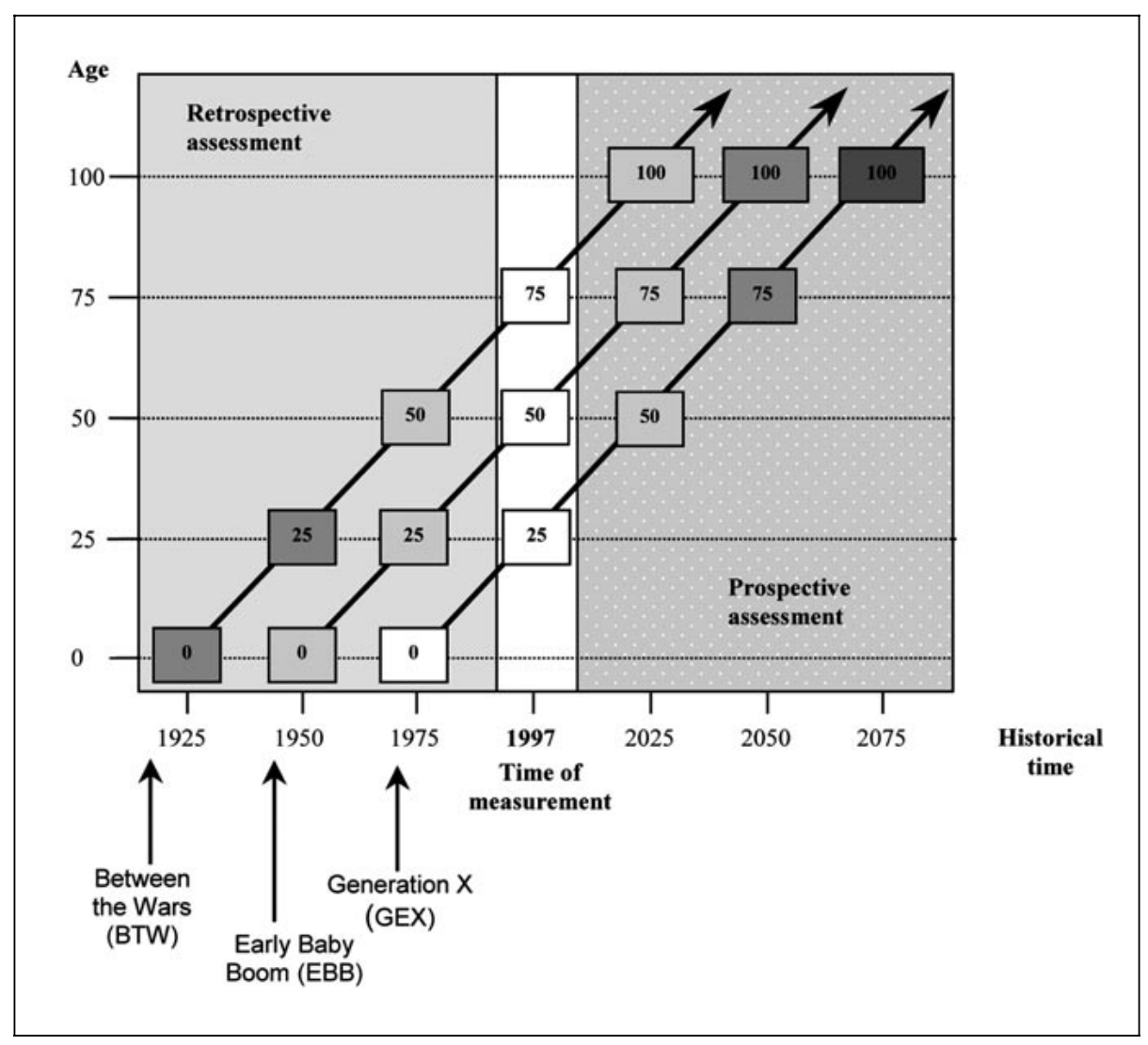

Fig. 1. Study design.

ration of life markers were identified and then coded according to the following content categories (Cohen's kappa: 0.90):

Death (for instance, loss of a close friend or relative)

Divorce

Education (school, apprenticeship, university, ongoing education)

Family/children (pregnancy, parenthood, caring for a family member)

Finances (financial problems, inheritance, salary upgrading, debts)

Growing up (growing up in a farm family, growing up with five siblings, being brought up strictly)

Health (diseases, worsening health, accidents, quitting smoking)

Housing (moving, renovation, buying or building a house)

Leaving home (moving out of parents' home)

Leisure (travelling, sports, music, community involvement)

Life events of others (divorce of parents, unemployment of father, disease of wife, education of children, career of husband)

Marriage

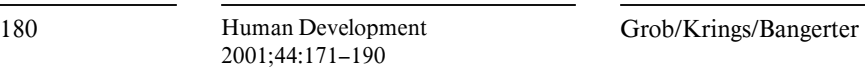


Military (military service during World War II, training camp, military courses)

New perspectives (being confronted with new perspectives through other persons, change of worldview after travelling)

Own death

Relationships (first intimate relationship, close friendships, breakup)

Self-related events (personal crisis, getting along in a changing society)

Societal events (joining the European Union, collapse of the welfare system, World War II, fall of the Berlin Wall)

Stay abroad (working two years abroad, emigration, immigration)

Work (start, change, quit, career, promotion, first job)

Other events (buying a car, voting rights, puberty, imprisonment)

Up to three related themes mentioned by the participant in relation to each life marker were also coded (percentage agreement: 66\%). For example, if a participant related that she could not complete secondary school because she had a large number of brothers and sisters and because her father had no money to pay for her books, the content category of the event was coded as education, and had two related themes: growing up and finances.

The evidence for the research questions will be presented in four sections. First, the distribution of life markers over the life span are reported, followed by the life span distribution of control expectancies. Then we will show which specific life markers were mentioned across the life span and, finally, in which developmental contexts people from different cohorts embedded educational life markers.

\section{Distribution of Life Markers Over the Life Span}

Figure 2 shows the mean number of life markers reported for each life decade and cohort. ${ }^{2}$ Overall, the distribution of life markers over the life span is very similar for all three cohorts. The number of life markers that were perceived as personally important for the individual life course increases from early childhood to young adulthood, reaching a peak between twenty and thirty years of age. Hereafter, the number of life markers decreases, increasing again for the current life period. These components reflect the typical division of the life span memory retrieval curve into components of childhood amnesia, reminiscence peak, and recency [Conway, 1997]. Furthermore, we found a sharp decrease in the number of prospective life markers for all cohorts. These similarities between the cohorts show that the participants reconstructed their life courses according to the same basic structure. Apparently, the crucial components of the life course take place in the second and third decades of life, i.e., during the transition to adulthood.

${ }^{2}$ Most of the 1491 life markers mentioned were dated by the participants or could be attributed unequivocally to a specific decade. This was not possible for 338 life markers ( $23 \%$ of the corpus), most of which were prospective. Therefore, these cases do not appear in figure 2. 


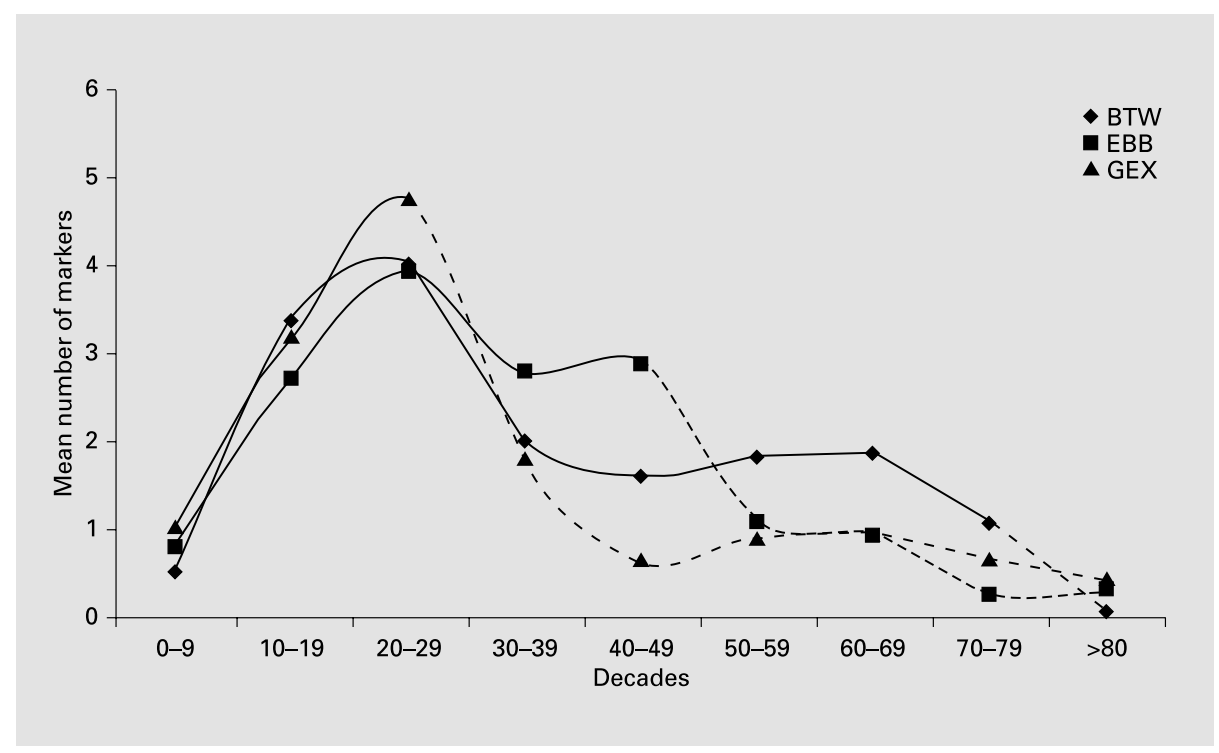

Fig. 2. Mean number of life markers reported for each life decade and cohort. Experienced decades are depicted in bold lines and expected decades in dashed lines.

\section{Control Expectancies}

In order to depict control expectancies with respect to life markers, the percentage of personally controlled life markers for each cohort and decade was calculated. Figure 3 reveals differences as well as similarities between cohorts. We hypothesized for each cohort an inverted u-curve with a shift towards a higher degree of personal control for the youngest cohort. The results almost reflected this assumption, however with some refinements. Similarities between the cohorts mainly concerned their perceptions of control over the life span. For all cohorts, the expected inverted u-curve was found: Globally, participants reported increasingly more control over life markers for the first three life decades reaching a peak between 20 and 30 (or 40) and hereafter a steady decline in personal control until very old age. Thus, all cohorts seemed to have similar experiences and expectations about the relation between personal control and age. Besides these similarities, we found some cohort differences.

First of all, BTW participants perceived considerably less control over the first three decades of life than those from the two younger cohorts. The most remarkable shift, however, concerned the EBB participants. In the first decade of their lives, they report similar levels of control as the BTW participants. For the second decade, however, levels of control shoot up to the level of the GEX participants. Historically, these participants experienced their teen years in the 1960s, a period of postwar growth in Switzerland and the prelude to the civil unrest of the end of the sixties. Experiencing these profound societal events during the sensitive period of the transition to adulthood may have contributed to the development of a greater sense of personal mastery for this cohort. Fifteen years later, GEX participants experienced their first decade of life and

$\begin{array}{ll}\begin{array}{l}\text { Human Development } \\ 2001 ; 44: 171-190\end{array} & \text { Grob/Krings/Bangerter } \\ \end{array}$




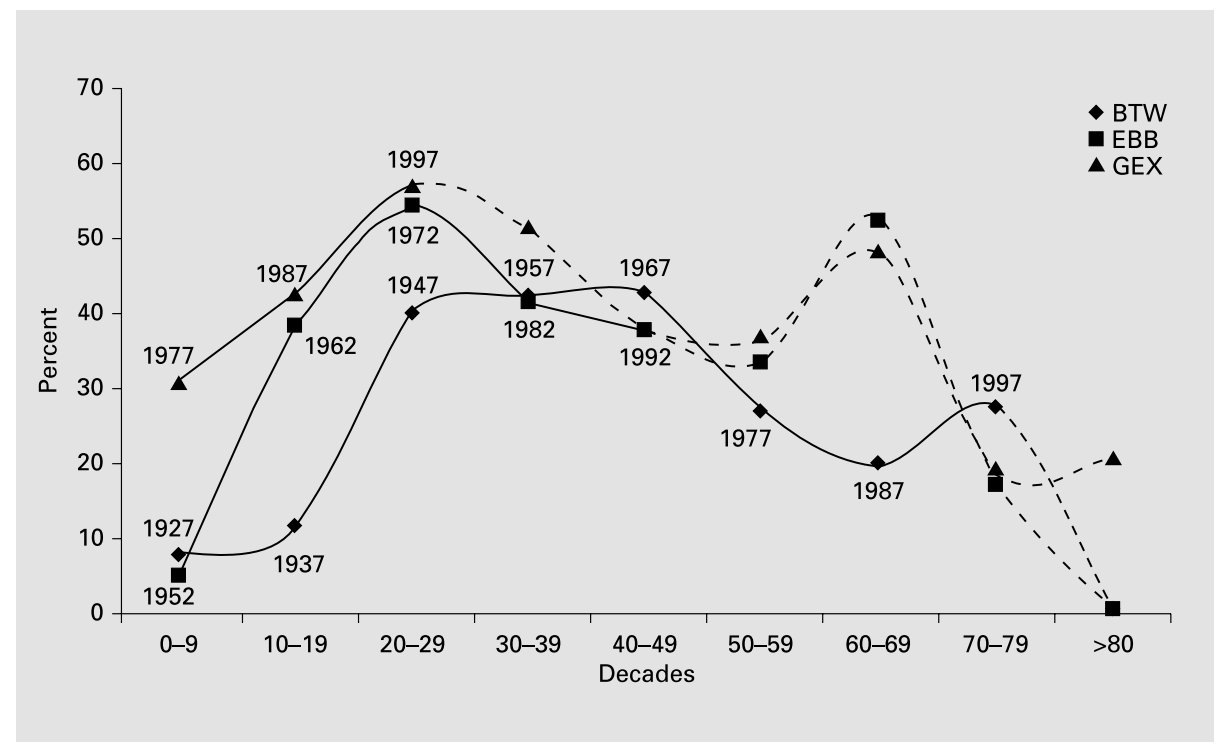

Fig. 3. Percentage of personally controlled life markers for each cohort and decade. Experienced decades are depicted in bold lines and expected decades in dashed lines. Historical time is indicated for each experienced decade and cohort.

reported comparable levels of control as the EBB cohort in their teens. This may reflect the fact that the new values established by the EBB generation constituted the basis for a different view of life experiences of the GEX participants which led them to develop higher levels of perceived control.

Taken together, these differences in the first three decades of life seem to reflect the effects of a historical shift towards individualization on the life course: People from these younger cohorts seem to perceive more opportunities to influence their biographies than those from older cohorts and thus become, in a way, makers of their own happiness. However, due to the study design, we cannot rule out the possibility of age effects rather than cohort differences for perceived control.

One unexpected result was an increase in expected control in the seventh decade for the EBB and GEX cohort. Many of the life markers that contributed to this evaluation were related to retirement. We interpreted the relative peak for these cohorts as an anticipation of more flexible retirement ages. Thus, this phenomenon illustrates the fact that expectations for the future life course are also based on assumptions about societal change (e.g., expected change in the domain of work). However, BTW participants reported a decrease in control in the seventh decade of life. This is probably due to the fact that, on the one hand, for this cohort, many participants were faced with compulsory retirement ( 62 years for women and 65 for men). On the other hand, many participants reported typically uncontrollable events such as health problems or death, either concerning the self or significant others. It is known that perceptions of internal control in various domains such as health or cognitive performance decrease for this age [e.g., Lachman, 1991; Heckhausen, 1999]. Thus, BTW participants were faced with the perspective of an impending and inexorable loss of control. The unexpected increase in 
control for the BTW participants around their current life period was found on markers related to leisure. Engaging in and/or selectively reporting leisure activities might constitute a way of coping with the impending losses.

\section{Content of Life Markers}

The findings on the content of life markers ${ }^{3}$ also reveal similarities as well as differences between the cohorts. Similarities between cohorts concern life markers occupying central positions in the first three quarters of life: For the first life quarter, education was mentioned by most participants (BTW: 22 participants; EBB: 19; GEX: 21), as were work-related events for the second and third quarters (BTW: 16, 19; EBB: 20, 20; GEX: $18,19)$. Work-related life markers of the third quarter frequently related to retirement. These results correspond to the so-called tripartition or chronologization of life into the three major segments of preparation for an occupation, working life, and retirement [Kohli, 1986]. Thus, experiences and expectations of life courses still seem to be standardized in the sense that, generally, people from all cohorts exhibited a similar structure for their biographies over most of the life span. For the fourth quarter, the picture was less clear: comparatively few life markers were mentioned; however, health- and death-related events, societal events, and own death were frequent mentions for all cohorts.

In spite of the fact that the life course seems structurally similar over the three cohorts, a number of differences were noted. For the first life quarter, three main aspects of these differences were identified. First, for the BTW participants, this life period was strongly incluenced by experiences related to the Second World War (mentioned by 14 of the 25 participants). For the other two cohorts, there was no comparable single historical event that shaped their lives so profoundly. Second, markers related to lifestyle and a preoccupation with the self (relationships, health, leisure, self-related) increased over cohorts (BTW: 1; EBB: 6; GEX: 7). Third, differences in life markers relating to marriage and founding a family were found, with GEX participants reporting less of these markers than the older participants (BTW: 4; EBB: 5; GEX: 1). Taken together, these findings reflect well-known demographic shifts and are consistent with the assumption of an increasing impact of individualization on the life course.

For the second life quarter, four main changes were apparent. First, a number of indicators pointed to the fact that for the GEX participants, questions of founding a family have become increasingly dissociated from marriage. Although many GEX participants expected to found a family ( 22 of 25; plus 1 person in the first life quarter), only a minority married or expected to marry ( 4 of 25 ; plus 1 person in the first quarter). In contrast, most BTW participants married (15 of 25; plus 7 in the first life quarter) and most of them had children (20 of 25 ). Thus, these findings highlight the decline of marriage as an institution. Indeed, a transitory phase in this process can be discerned by examining the lives of the EBB cohort. A majority of the EBB participants married (overall 19 persons; 9 in the first life quarter, and 10 of 25 in the second life quarter); however, about half of them divorced in the second quarter of life (10 of 25). Further-

\footnotetext{
${ }^{3}$ Grob, Krings and Bangerter [2000] present more detailed information about the results in this and the
} next section.

184 
more, for about half of the EBB participants, family and children were seldom mentioned in this life period (only 14 of 25 mentioned these).

Second, for the GEX participants, education was expected to extend well into the second quarter of life (BTW: 5; EBB: 4; GEX: 12). This reflects the current status of education - ongoing education - as a lifelong concern. Third, GEX participants frequently mentioned societal events they expected to influence their lives in this age period (BTW: 1; EBB: 6; GEX: 11). This finding has also been documented for adolescent populations [Nurmi, 1991]. Fourth, life markers related to leisure (BTW: 11; EBB: 12; GEX: 5), death (BTW: 11; EBB: 10; GEX: 4), and life events of others (BTW: 10; EBB: 8; GEX: 2) remarkably decreased for the GEX cohort. These declines are difficult to interpret and probably due to perspective, since this period lies in the future for this cohort.

For the third life quarter, two main changes were identified. First, mentions of life events of other persons as developmentally significant markers decreased across cohorts (BTW: 15; EBB: 7; GEX: 2). This might reflect a decrease in involvement with the lives of others. However, since this period was assessed prospectively for the EBB and GEX participants, an explanation in terms of perspective cannot be excluded. Second, the younger participants often mentioned future societal events which for them were in the future (BTW: 3; EBB: 11; GEX: 8). This was also found for the GEX participants for the previous life quarter. Thus, the tendency to consider societal events in the middle and long-term future when thinking about one's own life course seems to be a general phenomenon and not restricted to adolescence.

For the fourth life quarter, it is difficult to draw conclusions due to the small number of mentions. However, some trends from earlier life periods were obvious. For example, all cohorts again mentioned a number of future societal events (BTW: 6; EBB: 5; GEX: 7). And there is again a decline in involvement with life events of other persons (BTW: 5; EBB: 1; GEX: 0). Interestingly, one's own death as part of the individual biography was mentioned by 10 of 25 GEX participants, compared to a minority of the BTW participants (BTW: 7; EBB: 5; GEX: 10).

On a broad level, findings on the content of life markers point towards two main conclusions. First, a basic structure of the life course built around the three phases of preparing for an occupation, active work life, and life after retirement seems unchanged. Some traditional developmental tasks are still relevant. Second, a number of substantial changes were identified which can plausibly be attributed to effects of historical change.

\section{Developmental Contexts of Life Markers: Related Themes in Educational Narratives}

Analysis of related themes takes into account the fact that life markers belonging to the same category, experienced at comparable chronological ages, may have very different meanings for participants from different generations. Having experienced these markers in different historical contexts, participants from different generations may associate them with different experiences. These differences should also resurface in their narratives.

We focused on retrospective life markers related to education. They were perceived by each cohort as the most important life marker between birth and age 25 . In order to 
similar issues in intergenerational communication, see Coupland, Coupland \& Giles, 1991].

Educational narratives of GEX participants were very different, as seen in the following example taken from an interview with a 22-year old woman who focused on related themes of relationships and self:

Well there was one [event], I, at work, I started an apprenticeship as a cook in a restaurant and I didn't like it at all. So I tried to change, right? Actually, I wanted to quit. And then they told me I shouldn't do that, I should continue, they'd find me a job. And then also I had a few problems with myself and that was actually the time where I, that most personally shaped me, or which marked me the most. Where I also needed many people who pepped me up and told me what I should do, and I always orient myself a little to that. [Interviewer: 'So it was like a crisis? Which started with the problems in your apprenticeship?'] Yes it started then. I also had a separation, really hard, and then came all of that on top of it. And then afterwards, after all that, it gave me a direction again. I wanted to continue with the apprenticeship, and not for ever, but, like, it gave me a direction again, like, for three, four years.

In contrast to the preceding excerpts, a subject-centered narrative form is used. Here, the main actor is the narrator herself. Other actors are depicted abstractly and only through their relation to the narrator. The narrative is also characterized by an acute sensitivity to the feelings and desires of the self. Another point of interest is the selfevidence of the possibility of education. The possibility of choosing and accomplishing one's education is so taken for granted that it is never even touched upon. Instead, the narrative focuses on her 'inner' subjective world.

Thus, analysis of related themes reveals substantial thematic differences in narrative construction. Narratives of BTW participants were more often characterized by a focus on societal and military contexts in which their education was determined (BTW: 7 of 42 mentions; GEX: 0 of 28 mentions), on the family situation in which they grew up (BTW: 6 of 42; GEX: 1 of 28), on important events of significant others (BTW: 6 of 42; GEX: 0 of 28) and on the difficult financial situation of the family (BTW: 5 of 42; GEX 1 of 28). BTW participants insisted repeatedly on the extreme historical differences between the present and the time when they experienced their education. Thus, BTW narratives focused on the context of the event, rather than on the event itself. In contrast to this, narratives of GEX participants were more introspective. They revealed an extensive preoccupation with the self and with descriptions of processes of thinking and deciding (GEX: 9 of 28 mentions; BTW: 1 of 42 mentions) and the description of relations (GEX: 7 of 28; BTW: 3 of 42). Contexts were taken for granted, since they were rarely mentioned.

The thematic differences seem to be accompanied by differences in narrative technique. The examples suggest that being focused on the situation rather than on the person, BTW narrators often depicted other people as actors, and the self as passive. Sometimes the narrator was presented from a third-person perspective. In GEX narratives, the self seemed often to be the main protagonist, and other persons seemed to be depicted abstractly, through their relationship to the self. Actions undertaken by the self appeared to be mostly mental, e.g., thinking, wanting, and deciding. 


\section{Conclusions}

Our review of the literature and results suggest that a conceptualization of life must be cohort-specific. Individual development is embedded in proximal developmental settings, which in turn are determined by particular historical conditions. When this is taken into account, it can be shown that, from the oldest to the youngest cohorts, life courses studied were increasingly centered on the individual, even though evidence could be found that traditional developmental tasks are still relevant. That is, we have evidence for a profound impact of historical changes on the life course, but also evidence for substantial stability of a basic structure of the biography (tripartition of life).

Furthermore, we found a similar pattern for all cohorts concerning evaluative aspects of the life course in perceived control. This pattern approximately resembles an inverted u-curve: Control expectancy increased to a peak between the third and fourth life decade and decreased afterwards. In addition, we found a gradual shift of this curve with respect to cohort; i.e., participants from the GEX cohort perceived themselves as having more control over their life courses than participants from the BTW cohort.

Taken together, our results indicate individualization of life courses across the 20th century. This implies, among other things, a decrease in traditional values, more personal freedom, more openness, but also more uncertainty about being able to successfully realize one's intended life course because more choices have to be made. Questions that remain are which resources and competences people need in order to successfully cope with these emerging developmental pressures, to what extent these resources and competences are currently available, and finally, to what extent these findings are generalizeable beyond the Swiss case to other cultural settings.

Of course, our study has an important limitation. We interpret the results as if they were generated by a longitudinal study; i.e., treating age, cohort, and time as separable, although we have a cross-sectional study incorporating retrospective and prospective measures, which complicates interpretation of the results. The design does not allow clear attribution of group differences to either age differences or to historical changes. However, we think that the seriousness of this problem depends to some degree on the research object. Given the fact that we are studying connections between historical factors and individual biographies, we have access to other, independent sources of data which inform us as to how the varying historical contexts have generated different developmental setting for the three cohorts we studied. Thus, it is possible to discern which results may plausibly be attributed to cohort differences and which are probably the result of age and perspective differences.

As a final remark, we would like to emphasize an important issue which goes beyond methodological considerations to epistemological ones. It is the issue of how such basic questions as the connection between historical change and individual life courses can be studied appropriately. It goes without saying that a prospective longitudinal study would be an appropriate procedure. However, it is unlikely that such an undertaking can be realized, given temporal and financial restrictions. But even if these restrictions were overcome, one would run into other problems that have to do with the change of research questions across time and across cultures.

This is where methodological problems become epistemological ones because it is unlikely that socially shared concepts of personal control and development have remained unchanged over the past century. For instance, the meaning of 'expecting personal control over consequential events' has itself evolved over this period. In differ-

$\begin{array}{ll}\begin{array}{l}\text { Human Development } \\ 2001 ; 44: 171-190\end{array} & \text { Grob/Krings/Bangerter }\end{array}$


ent historical epochs, people will understand such questions differently. And, furthermore, it is unlikely that scientific concepts have remained unchanged over this period of time. For instance, research about personal control expectancy was not yet established at the time the oldest cohort of this study entered adulthood. In other words, scientific concepts themselves and how they are studied have a history. Hence, both science and objects of scientific study are products of their time and culture, and, in turn, co-determine their cultural contexts.

\section{References}

Baltes, P.B. (1997). On the incomplete architecture of human ontogeny: Selection, optimization, and compensation as foundation of developmental theory. American Psychologist, 52, 366-380.

Bamberg, M.G.W. (Ed.). (1997a). Oral versions of personal experience. Mahwah: Lawrence Erlbaum.

Bamberg, M.G.W. (Ed.). (1997b). Narrative development: Six approaches. Mahwah: Lawrence Erlbaum.

Baumeister, R.F. (1991). Meanings of life. New York: Guilford.

Beck, U. (1986). Risikogesellschaft. Auf dem Weg in eine andere Moderne. [Risk society: On the way to another modernity.] Frankfurt am Main: Suhrkamp.

Berry, J.M., \& West, R.L. (1993). Cognitive self-efficacy in relation to personal mastery and goal setting across the life span. International Journal of Behavioral Development, 16, 351-379.

Brandtstädter, J. (1997). Action, culture and development: Points of convergence. Culture and Psychology, 3, 335352.

Bronfenbrenner, U. (1979). The ecology of human development. Cambridge, MA: Harvard University Press.

Church, A.T., \& Lonner, W.J. (1998). The cross-cultural perspective in the study of personality: Rationale and current research. Journal of Cross-Cultural Psychology, 29, 32-62.

Conway, M.A. (1997). The inventory of experience: Memory and identity. In J.W. Pennebaker, D. Paez \& B. Rimé (Eds.), Collective memory of political events: Social psychological perspectives (pp. 21-45). Mahwah, NJ: Erlbaum.

Coupland, N., Coupland, J., \& Giles, H. (1991). Language, society and the elderly: Discourse, identity and aging. Oxford: Blackwell.

De Vries, B., \& Watt, D. (1996). A lifetime of events: Age and gender variations in the life story. International Journal of Aging and Human Development, 42, 81-102.

Elder, G.H. Jr. (1974). Children of the Great Depression: Social change in life experience. Chicago: University of Chicago Press.

Elder, G.H. Jr. (1998). The life course as developmental theory. Child Development, 69, 1-12.

Erikson, E.H. (1959). Identity and the life cycle. New York: International University Press.

Fend, H. (2000). The cultural scripts of control and individualization: Consequences for growing up during adolescence in modern societies. In W.J. Perrig \& A. Grob (Eds.), Control of human behavior, mental processes, and awareness (pp. 487-503). Mahwah: Lawrence Erlbaum Associates.

Fitzgerald, J.M. (1988). Vivid memories and the reminiscence phenomenon: The role of a self narrative. Human Development, 31, 261-273.

Grob, A. (1998, June). Identifying societal change by studying biographies of people from different cohorts. Paper to the VIth Biennial Conference of the European Association for Research on Adolescence, Budapest, Hungary.

Grob, A. (2000). Dynamics of perceived control across adolescence and adulthood. In W.J. Perrig \& A. Grob (Eds.), Control of human behavior, mental processes, and awareness (pp. 325-344). Mahwah: Lawrence Erlbaum Associates.

Grob, A., Krings, F., \& Bangerter, A. (2000). Life markers in biographies of three Swiss cohorts. Research Report No. 72, Institute of Psychology, University of Basel, Switzerland.

Grob, A., Little, T.D., \& Wanner, B. (1999). Control judgements across the life span. International Journal of Behavioral Development, 23, 833-854.

Grundmann, M. (1996). Historical context of father absence: Some consequences for the family formation of German men. International Journal of Behavioral Development, 19, 415-432.

Hareven, T.K. (1995). Historical perspectives on the family and aging. In R. Blieszner \& V.H. Bedford (Eds.), Handbook of aging and the family (pp. 13-31). Westport, CT: Greenwood Press.

Havighurst, R.J. (1948). Developmental tasks and education. New York: McKay.

Heckhausen, J. (1999). Developmental regulation in adulthood: Age-normative and sociostructural constraints as adaptive challenges. Cambridge: Cambridge University Press.

Heckhausen, J., \& Krüger, J. (1993). Developmental expectations for the self and most other people: Age grading in three functions of social comparison. Developmental Psychology, 29, 539-548.

Held, T. (1986). Institutionalization and deinstitutionalization of the life course. Human Development, 29, $157-162$. 
Hernandez, D.J. (1993). America's children: Resources from family, government, and the economy. New York: Russell Sage Foundation.

Imhof, A.E. (1986). Life course patterns of women and their husbands: 16th to 20th century. In A.B. Sørensen, F.E. Weinert \& L.R. Sherrod (Eds.), Human development and the life course: Multidisciplinary perspectives (pp. 247-270). Hillsdale, NJ: Erlbaum.

Jüttemann, G., \& Thomae, H. (Eds.). (1987). Biographie und Psychologie. [Biography and psychology]. Berlin: Springer.

Jüttemann, G., \& Thomae, H. (Eds.). (1998). Biographische Methoden in den Humanwissenschaften [Biographical methods in humanities]. Weinheim: Psychologie Verlags Union.

Kaelble, H. (1997). Der Wandel der Erwerbsstruktur in Europa im 19. und 20. Jahrhundert [The change of employment sectors in Europe in the 19th and 20th century]. Historical Social Research, 22, 5-28.

Kleining, G. (1998). Heuristik zur Erforschung von Biographien und Generationen [Heuristics for investigation of biographies and generations]. In G. Jüttemann \& H. Thomae (Eds.), Biographische Methoden in den Humanwissenschaften (pp. 175-192). Weinheim: Psychologie Verlags Union.

Kogan, N. (1990). Personality and aging. In J.E. Birren \& K.W. Schaie (Eds.), Handbook of the psychology of aging (pp. 330-346). San Diego: Academic Press.

Kohli, M. (1985). Die Institutionalisierung des Lebenslaufes [The institutionalization of the life course]. Kölner Zeitschrift für Soziologie und Sozialpsychologie, 37, 1-29.

Kohli, M. (1986). Social organization and subjective construction of the life course. In A.B. Sørensen, F.E. Weinert \& L.R. Sherrod (Eds.), Human development and the life course: Multidisciplinary perspectives (pp. 271-292). Hillsdale, NJ: Erlbaum.

Kohli, M. \& Meyer, J.W. (1986). Social structure and social construction of life stages. Human Development, 29, $145-149$.

Lachman, M.E. (1986). Locus of control in aging research: A case for multidimensional and domain-specific assessment. Psychology and Aging, 1, 34-40.

Lachman, M.E. (1991). Perceived control over memory aging: Developmental and intervention perspectives. Journal of Social Issues, 47, 159-175.

Lerner, R.M. (1996). Relative plasticity, integration, temporality, and diversity in human development: A developmental contextual perspective about theory, process, and method. Developmental Psychology, 32, 781-786.

Magnusson, D. (1993). Human ontogeny: A longitudinal perspective. Cambridge: Cambridge University Press.

Mannheim, K. (1952). The problem of generations. In K. Mannheim (Ed.), Essays on the sociology of knowledge (pp. 276-321). London: Routledge \& Keegan Paul.

Mayer, K.U. (1986). Structural constraints on the life course. Human Development, 29, 163-170.

Neugarten, B.L. (1979). Time, age, and the life cycle. American Journal of Psychiatry, 136, 887-894.

Neugarten, B.N., \& Hagestad, G.O. (1976). Age and the life course. In R. Binstock \& E. Shanas (Eds.), Handbook of aging and social sciences. New York: Van Nostrand Reinhold.

Nurmi, J.-E. (1991). How do adolescents see their future? A review of the development of future orientation and planning. Developmental Review, 11, 1-59.

Rosenthal, G. (1993). Reconstruction of life stories. Principles of selection in generating stories for narrative biographical interviews. In R. Josselson \& A. Lieblich (Eds.), The narrative study of lives (pp. 59-91). Newbury Park: Sage.

Rubin, D.C., Wetzler, S.E., \& Nebes, R.D. (1986). Autobiographical memory across the lifespan. In D.C. Rubin (Ed.), Autobiographical memory (pp. 202-221). Cambridge: Cambridge University Press.

Sarbin, T.R. (Ed.). (1986). Narrative psychology: The storied nature of human conduct. New York: Praeger.

Settersten, R.A. Jr. (1997). The salience of age in the life course. Human Development, 40, 257-281.

Settersten, R.A. Jr., \& Hagestad, G.O. (1996a). What's the latest? Cultural age deadlines for family transitions. The Gerontologist, 36, 178-188.

Settersten, R.A. Jr., \& Hagestad, G.O. (1996b). What's the latest? II. Cultural age deadlines for educational and work transitions. The Gerontologist, 36, 602-613.

Skinner, E.A. (1996). A guide to constructs of control. Journal of Personality and Social Psychology, 71, 549-570.

Sørensen, A.B. (1986). Social structure and mechanisms of life-course processes. In A.B. Sørensen, F.E. Weinert \& L.R Sherrod (Eds.), Human development and the life course: Multidisciplinary perspectives (pp. 177-198). Hillsdale, NJ: Erlbaum.

Straub, J. (1989). Historisch-psychologische Biographieforschung. Theoretische, methodologische und methodische Argumentationen in systematischer Absicht [Historical psychological biography research. Theoretical, methodological, and methodical arguments in systematic perspective]. Heidelberg: Asanger.

Triandis, H.C. (1997). Cross-cultural perspectives on personality. In R. Hogan, J.A. Johnson \& S.R. Briggs (Eds.), Handbook of personality psychology (pp. 439-464). San Diego, CA: Academic Press.

U.S. Bureau of the Census (1997). Statistical Abstract of the United States: 1997. Washington, DC.

Welch, D.C., \& West, R.L. (1995). Self-efficacy and mastery: Its application to issues of environmental control, cognition, and aging. Developmental Review, 15, 150-171.

Zapf, W. (1995). Entwicklung und Sozialstruktur moderner Gesellschaften [Development and social structure of modern societies]. In H. Korte \& B. Schäfers (Eds.), Einführung in die Hauptbegriffe der Soziologie (pp. 181-191). Opladen: Leske \& Budrich.

Zepelin, H., Sills, R.A., \& Heath, M.W. (1986-87). Is age becoming irrelevant? An explanatory study of perceived age norms. International Journal of Aging and Human Development, 24, 241-256.

${ } }$
$2001 ; 44: 171-190$$\quad \overline{\text { Grob/Krings/Bangerter }}$

